might ease the access of the ion to Ps. However, the fact that $k^{\prime}$ does not change for $r$ values much higher than those corresponding to the condensation limit makes this interpretation unlikely. (ii) When one considers that POE behaves similarly to the polyions, the changes in $k^{\prime}$ can arise from viscosity effects as yet unclear.

The mechanism of the reaction between $P s$ and metal ions is not yet well understood. If part of the quenching is undoubtedly due to spin conversion, other reactions may compete with this process with varying contributions as the temperature is changed. It is possible that the polymer affects these various processes. More experiments are obviously needed for a better understanding of the mechanism of the reaction between $\mathrm{Ps}$ and $\mathrm{Co}^{2+}$ ions.

\section{Conclusion}

The present work demonstrates that the positron life-

(24) H. Diebler, M. Eigen, G. Ilgenfritz, G. Maass, and R. Winkler, Pure Appl. Chem., 20, 93 (1969). time spectroscopy can give information which is twofold, concerning the fields of Ps chemistry and of polyaniondivalent cation interactions.

Regarding the Ps reactions, we have shown that divalent ions bound with loss of their first hydration shell are not reactive toward Ps. On the other hand, condensed ions which have retained their hydration shells have essentially the same quenching ability as in pure aqueous solutions. This would suggest that Ps must enter the first hydration shell of the divalent ion before reacting.

For the polyion-cation interactions, our experiments have yielded results in qualitative and quantitative agreement with those obtained by using other techniques for the Co-PSS, Co-PP, and Co-Gantrez $(\alpha=0.95)$ systems, thus pointing to the potential suitability of the positron annihilation technique in this field of research.

Acknowledgment. S.M. thanks the French Foreign Ministry and the Mexican National Council of Science and Technology (CONACYT) for financial support.

\title{
Thermochemical Investigations of Gas-Llquld Chromatography. Partition Coefficients of Inert Solutes on Self-Associating BInary Solvent Mixtures
}

\author{
William E. Acree, Jr. \\ Department of Chemistry, University of Kansas, Lawrence, Kansas 66045 (Recelved: August 21, 1981; \\ In Final Form: November 13, 1981)
}

\begin{abstract}
A conventional nonelectrolyte solution model which has led to successful predictive equations for the partial molar excess properties of a solute in simple binary solvent systems is extended to include self-associating solvent components. An expression is developed and tested for its ability to describe gas-liquid partition coefficients in mixed solvents from measurements in the pure solvents. For $n$-hexane, $n$-heptane, and cyclohexane on blended mixtures of $n$-hexadecane and $n$-octadecane with $N, N$-dibutyl-2-ethylhexylamide, the newly derived expression is found to describe the chromatographic data to within $2 \%$.
\end{abstract}

\section{Introduction}

During the past decade, gas-liquid chromatography has proven to be an accurate and convenient method for measuring vapor-liquid equilibria data for nonelectrolyte systems. This is particularly true in the low concentration regions (infinite dilution) normally inaccessible by conventional static vapor pressure techniques. The data generally obtained include the chromatographic partition coefficient $K_{\mathrm{R}}$ and the Raoult's law activity coefficients of the volatile solute (component $A$ ) at infinite dilution $\gamma^{\infty}{ }_{A}$ in the stationary liquid phase.

Binary liquid mixtures have also been investigated by a large number of individuals. There are two main purposes for this type of investigation. The first is the attempt to control the selectivity of a chromatographic column through the use of mixed liquid phases and the second is an attempt to measure equilibrium constants for weak association complexes, such as charge transfer and hydrogen-bonding complexes, between the solute and one of the solvent components. This later application of gasliquid chromatography has invoked a great deal of controversy, especially in regards to the appropriate thermodynamic description of mixed liquid phases. ${ }^{1-17}$

(1) J. H. Purnell and J. M. Vargas de Andrade, J. Am. Chem. Soc., 97, 3585 (1975).
Purnell, Laub, and their co-workers ${ }^{1-5}$ have shown that solute retention behavior with binary liquid mixtures (B $+C$ ) can be described by a simple volume fraction average of the partition coefficients on the pure solvents $\left(K_{\mathrm{R}(\mathrm{B})}^{0}\right.$ and $\left.K_{\mathrm{R}(\mathrm{C})}^{0}\right)$

(2) J. H. Purnell and J. M. Vargas de Andrade, J. Am. Chem. Soc., 97 , 3590 (1975).

(3) R. J. Laub and J. H. Purnell, J. Am. Chem. Soc., 98, 30 (1976).

(4) R. J. Laub and J. H. Purnell, J. Am. Chem. Soc., 98, 35 (1976).

(5) R. J. Laub, D. E. Martire, and J. H. Purnell, J. Chem. Soc., Faraday Trans. 2, 213 (1978).

(6) M. W. P. Harbison, R. J. Laub, D. E. Martire, J. H. Purnell, and P. S. Williams, J. Phys. Chem., 83, 1262 (1979).

(7) C. L. Young, J. Chromatogr. Sci., 8, 103 (1970)

(8) D. E. Martire, Anal. Chem., 48, 398 (1976).

(9) H. L. Liao, D. E. Martire, and J. P. Sheridan, Anal. Chem., 45 2087 (1973).

(10) D. E. Martire, Anal. Chem., 46, 1712 (1974).

(11) A. J. Ashworth and D. M. Hooker, J. Chromatogr., 131, 399 (1977).

(12) P. F. Tiley, J. Chromatogr., 179, 247 (1979).

(13) R. W. Perry and P. F. Tiley, J. Chem. Soc., Faraday Trans. 1, 74, 1655 (1978).

(14) S. D. Christian, E. E. Tucker, and A. Mitra, J. Chem. Soc., Faraday Trans. 1, 73, 537 (1977).

(15) E. E. Tucker and S. D. Christian, J. Am. Chem. Soc., 100, 1418 (1978).

(16) W. E. Acree, Jr., and G. L. Bertrand, J. Phys. Chem., 83, 2355 (1979).

(17) C.-F. Chien, M. M. Kopecni, R. J. Laub, and C. A. Smith, J. Phys. Chem., 85, 1864 (1981). 


$$
K_{\mathrm{R}(\mathrm{BC})}=\phi_{\mathrm{B}} K_{\mathrm{R}(\mathrm{B})}^{0}+\phi_{\mathrm{C}} K_{\mathrm{R}(\mathrm{C})}^{0}
$$

irrespective of the complexing nature of the system, and suggested that this linear relationship may imply "the prospect of a coherent theory of solutions of a generally not hitherto visualized". ${ }^{5}$ A slightly different form of eq 1

$$
\begin{gathered}
K_{\mathrm{R}(\mathrm{BC})}=K_{\mathrm{R}(\mathrm{B})}^{0}\left[1+K_{\mathrm{AC}} C_{\mathrm{C}}\right] \\
K_{\mathrm{AC}}=\frac{\left[K_{\mathrm{R}(\mathrm{C})}^{0}-K_{\mathrm{R}(\mathrm{B})}^{0}\right] \bar{V}_{\mathrm{C}}}{K_{\mathrm{R}(\mathrm{B})}^{0}}
\end{gathered}
$$

enables the estimation of the solute-solvent molar equilibrium constant $K_{\mathrm{AC}}$ from chromatographic measurements. Despite the fact that eq 1 provides a reasonable mathematical representation of several hundred ternary systems, it cannot be rigorously derived from conventional nonelectrolyte solution models. The expression can be readily derived, though, on the basis that the two liquid phases "exist in their macroscopic solutions as microscopically immiscible groups of like molecules". ${ }^{3}$

Acree and Bertrand ${ }^{16}$ demonstrated that the linear relationship between partition coefficients and volume fractions is a nongeneral thermodynamic relationship. The authors indicated, however, that it may be taken as a very good approximation of a more general expression which is based on a realistic (though still approximate) thermodynamic model. Acree and Bertrand derived the following expression for partition coefficients in systems having 1:1 solute-solvent complexation

$$
\begin{aligned}
\ln K_{\mathrm{R}(\mathrm{BC})}= & \phi_{\mathrm{B}} \ln K_{\mathrm{R}(\mathrm{B})}^{0}+\phi_{\mathrm{C}} \ln K_{\mathrm{R}(\mathrm{C})}^{\prime}+ \\
& \ln \left(1+K_{\mathrm{AC}} \phi_{\mathrm{C}}\right)+\frac{\bar{V}_{\mathrm{A}} \Delta \bar{G}^{\mathrm{fh}}{ }_{\mathrm{BC}}}{\left(X_{B} \bar{V}_{B}+X_{\mathrm{C}} \bar{V}_{\mathrm{C}}\right) R T}
\end{aligned}
$$

based on their nearly ideal binary solvent model. Inspection of eq 4 reveals that it reduces to a linear form

$$
K_{\mathrm{R}(\mathrm{BC})}=K_{\mathrm{R}(\mathrm{B})}^{0}\left[1+K_{\mathrm{AC}}^{\prime} \phi_{\mathrm{C}}\right]
$$

whenever the ratio of the partition coefficients of the $u$ complexed solute in the pure solvents $K_{\mathrm{R}(\mathrm{B})}^{0} / K_{\mathrm{R}(\mathrm{C})}^{\prime}$ is unity and the excess molar Gibbs free energy of the binary solvent pair (relative to Flory-Huggins entropy) $\Delta \bar{G}^{\mathrm{h}_{\mathrm{BC}}}$ equals zero. Subsequent studies by Acree et al..$^{18-21}$ have shown that the experimental solubilities of benzil and $p$-benzoquinone in binary solvent mixtures containing carbon tetrachloride exhibit considerable deviations from eq 1 (eq 1 expressed in terms of solubilities in the manner outlined in ref 16), with some of the deviations as large as $100 \%$. While it might be argued by some that the failure of eq 1 in these two instances is a result of departure from infinite dilution or is a result of complexation between the solutes and carbon tetrachloride, it should be noted that conventional solution models describe the benzil and $p$ benzoquinone solubilities to within a maximum deviation of $6 \%$ without introducing a single equilibrium constant. Dipole moment measurements of benzil in benzene and carbon tetrachloride have been interpreted as evidence for specific interactions of benzil with benzene but not with carbon tetrachloride. ${ }^{22}$ The gas-liquid chromatographic

(18) W. E. Acree, Jr., Ph.D. Dissertation, University of MissouriRolla, 1981.

(19) W. E. Acree, Jr., and J. H. Rytting, J. Pharm. Sci., in press.

(20) W. E. Acree, Jr., and G. L. Bertrand, manuscript in preparation.

(21) W. E. Acree, Jr., and J. H. Rytting, Int. J. Pharm., in press.

(22) P. A. Hopkins, R. J. W. LeFevre, L. Radom, and G. L. D. Ritchie, J. Chem. Soc. B, 574 (1971). retention behavior of carbon tetrachloride and chloroform on a benzil stationary phase has been explained by Vernon $^{23}$ in terms of London or simple dispersion forces in the case of carbon tetrachloride and in terms of hydrogen bonding in the case of chloroform.

Recently, Chien et al..$^{17}$ attributed the nonlinear behavior of several solutes ( $n$-heptane, $n$-hexane, and cyclohexane) on blended mixtures of $n$-hexadecane and $n$-octadecane with $N, N$-dibutyl-2-ethylhexylamide to the self-association of the amide. Earlier studies involving dielectric properties had also suggested that $N, N$-dibutyl-2-ethylhexylamide undergoes a weak reversible dimerization with the equilibrium constant in hexane solutions $K_{\mathrm{D}}=0.20 \mathrm{dm}^{3} / \mathrm{mol}^{24}$ being nearly temperature independent. An extended form of eq 1

$$
\begin{aligned}
& K_{\mathrm{R}(\mathrm{BC})}=\phi_{\mathrm{B}} K_{\mathrm{R}(\mathrm{B})}^{0}+\phi_{\mathrm{C}} K^{0}{ }_{\mathrm{R}\left(\mathrm{C}_{2}\right)}+ \\
& \frac{\bar{V}_{\mathrm{C}_{1}}\left[K_{\mathrm{R}\left(\mathrm{C}_{1}\right)}^{0}-K_{\mathrm{R}\left(\mathrm{C}_{2}\right)}^{0}\right]}{4 K_{\mathrm{D}}}\left[-1+\left(1+8 K_{\mathrm{D}} \phi_{\mathrm{C}} / \bar{V}_{\mathrm{C}_{1}}\right)^{1 / 2}\right]
\end{aligned}
$$

modified to include the dimerization of component $\mathrm{C}$, described the experimental data to within $1.5 \%$. By way of conclusion, Chien et al. asserted that expressions derived from conventional solution models "must yield one or another alternatives of eq 1 and 6 at least by approximation in order to conform with experiment".

The purpose of this paper is to point out the extension of conventional nonelectrolyte solution models to self-associating binary solvent systems leads to a relatively simple expression which approximates (or nearly approximates) the behavior of eq 6 in the six systems considered here. As a result, the controversy regarding the correct thermodynamic description of mixed liquid phases remains unresolved, at least with respect to chromatographic applications. Expressions derived from the microscopic partition model and conventional solution models do have different mathematical forms though, and these differences might be useful in designing future gas-liquid chromatographic investigations on self-associating binary solvent systems. The subject certainly warrants further study. From an entirely practical standpoint, the description of self-associating binary solvent systems via conventional nonelectrolyte solution models may offer several advantages not realized with the microscopic partition model. Expressions of the conventional models, because of their logarithmic nature, appear more ideally suited for relative retention indices and the predictive application of these expressions require only an a priori knowledge of the indices in the pure solvents and the numerical value of the dimerization constant.

\section{Development of Model for Self-Associating Binary Solvent Systems}

The nearly ideal binary solvent (NIBS) treatment has been shown to be quite dependable for estimating heats of solution, ${ }^{25}$ gas-liquid partition coefficients, ${ }^{16,27}$ and solubilities ${ }^{18-21,26}$ in binary solvent systems which are free of association. The form of the NIBS equation which has been most successful for describing the excess chemical potential of solutes is based on a simple mixing model of a multicomponent system

(23) F. Vernon, J. Chromatogr., 63, 249 (1971).

(24) M. M. Kopecni, R. J. Laub, and Dj. M. Petkovic, J. Phys. Chem., 85, 1595 (1981).

(25)

(26) W. E. Acree, Jr., and G. L. Bertrand, J. Phys. Chem., 81, 1170 (1977).

(27) W. E. Acree, Jr., and J. H. Rytting, Anal. Chem., 52, 1764 (1980). 
$\Delta G_{1,2, \ldots, N}^{\operatorname{mix}}=R T \sum_{i=1}^{N} n_{i} \ln \phi_{i}+\left[\sum_{i=1}^{N} n_{i} \bar{V}_{i}\right]\left[\sum_{i=1 j>i} \sum_{i} \phi_{j} A_{i j}\right]$

in which $n_{i}$ is the number of moles of a component, $\bar{V}_{i}$ is the molar volume of a pure liquid, $\phi_{i}$ is volume fraction, and $A_{i j}$ is a binary interaction parameter which is independent of solvent composition. Although I have not directly tested the applicability of eq 7 for self-associating solvents, Renon and Prausnitz ${ }^{28}$ and Nagata ${ }^{29,30}$ have used this simple mixing model as the starting point in their thermodynamic treatments of alcohol-hydrocarbon mixtures. The success that these approaches have shown in their ability to predict the thermodynamic excess properties of ternary alcohol-two hydrocarbon systems from measured binary data suggests that eq 7 might also provide a reasonable description of the thermochemical properties of a solute in binary solvent mixtures having a self-associating component.

The application of eq 7 to the quaternary system (A, B, $\mathrm{C}_{1}$, and $\mathrm{C}_{2}$ ) takes the form of

$$
\begin{aligned}
& \Delta G^{\text {mix }}= \\
& R T\left[n_{\mathrm{A}} \ln \phi_{\mathrm{A}}+n_{\mathrm{B}} \ln \phi_{\mathrm{B}}+n_{\mathrm{C}_{1}} \ln \phi_{\mathrm{C}_{1}}+n_{\mathrm{C}_{2}} \ln \phi_{\mathrm{C}_{2}}\right]+ \\
& \left(n_{\mathrm{A}} \bar{V}_{\mathrm{A}}+n_{\mathrm{B}} \bar{V}_{\mathrm{B}}+n_{\mathrm{C}_{1}} \bar{V}_{\mathrm{C}_{1}}+n_{\mathrm{C}_{2}} \bar{V}_{\mathrm{C}_{2}}\right)\left[\phi_{\mathrm{A}} \phi_{\mathrm{B}} A_{\mathrm{AB}}+\right. \\
& \left.\phi_{\mathrm{A}} \phi_{\mathrm{C}_{1}} A_{\mathrm{AC}_{1}}+\phi_{\mathrm{A}} \phi_{\mathrm{C}_{2}} A_{\mathrm{AC}_{2}}+\phi_{\mathrm{B}} \phi_{\mathrm{C}_{1}} A_{\mathrm{BC}_{1}}+\phi_{\mathrm{B}} \phi_{\mathrm{C}_{2}} A_{\mathrm{BC}_{2}}\right]
\end{aligned}
$$

the only assumption being that the monomer-dimer interaction parameter $A_{\mathrm{C}_{1} \mathrm{C}_{2}}$ equals zero. The chemical potentials of the individual components relative to the pure liquids $\left(\mu_{i}^{*}\right)$ are obtained through the appropriate differentiation

$$
\begin{aligned}
& \mu_{\mathrm{A}}-\mu_{\mathrm{A}}^{*}= \\
& R T\left[\ln \phi_{\mathrm{A}}+1-\frac{\bar{V}_{\mathrm{A}}}{\hat{V}_{\mathrm{soln}}}\right]+\bar{V}_{\mathrm{A}}\left[\phi_{\mathrm{B}}\left(1-\phi_{\mathrm{A}}\right) A_{\mathrm{AB}}+\phi_{\mathrm{C}_{1}}(1-\right. \\
& \left.\left.\phi_{\mathrm{A}}\right) A_{\mathrm{AC}_{1}}+\phi_{\mathrm{C}_{2}}\left(1-\phi_{\mathrm{A}}\right) A_{\mathrm{AC}_{2}}-\phi_{\mathrm{B}} \phi_{\mathrm{C}_{1}} A_{\mathrm{BC}_{1}}-\phi_{\mathrm{B}} \phi_{\mathrm{C}_{2}} A_{\mathrm{BC}_{2}}\right](9) \\
& \mu_{\mathrm{B}}-\mu^{*}{ }_{\mathrm{B}}= \\
& R T\left[\ln \phi_{\mathrm{B}}+1-\frac{\bar{V}_{\mathrm{B}}}{\hat{V}_{\mathrm{soln}}}\right]+V_{\mathrm{B}}\left[\phi_{\mathrm{A}}\left(1-\phi_{\mathrm{B}}\right) A_{\mathrm{AB}}+\phi_{\mathrm{C}_{1}}(1-\right. \\
& \left.\left.\quad \phi_{\mathrm{B}}\right) A_{\mathrm{BC}_{1}}+\phi_{\mathrm{C}_{2}}\left(1-\phi_{\mathrm{B}}\right) A_{\mathrm{BC}_{2}}-\phi_{\mathrm{A}} \phi_{\mathrm{C}_{1}} A_{\mathrm{AC}_{1}}-\phi_{\mathrm{A}} \phi_{\mathrm{C}_{2}} A_{\mathrm{AC}_{2}}\right]
\end{aligned}
$$

$$
\begin{aligned}
& \mu_{\mathrm{C}_{1}}-\mu^{*} \mathrm{C}_{1}= \\
& R T\left[\ln \phi_{\mathrm{C}_{1}}+1-\frac{\bar{V}_{\mathrm{C}_{1}}}{\hat{V}_{\mathrm{soln}}}\right]+\bar{V}_{\mathrm{C}_{1}}\left[\phi_{\mathrm{A}}\left(1-\phi_{\mathrm{C}_{1}}\right) A_{\mathrm{AC}_{1}}+\right. \\
& \left.\quad \phi_{\mathrm{B}}\left(1-\phi_{\mathrm{C}_{1}}\right) A_{\mathrm{BC}_{1}}-\phi_{\mathrm{A}} \phi_{\mathrm{B}} A_{\mathrm{AB}}-\phi_{\mathrm{A}} \phi_{\mathrm{C}_{2}} A_{\mathrm{AC}_{2}}-\phi_{\mathrm{B}} \phi_{\mathrm{C}_{2}} A_{\mathrm{BC}_{2}}\right]
\end{aligned}
$$

where $\hat{V}_{\text {soln }}$ is the molar volume of the true solution

$$
\frac{1}{\hat{V}_{\text {soln }}}=\frac{\phi_{\mathrm{A}}}{\bar{V}_{\mathrm{A}}}+\frac{\phi_{\mathrm{B}}}{\bar{V}_{\mathrm{B}}}+\frac{\phi_{\mathrm{C}_{1}}}{\bar{V}_{\mathrm{C}_{1}}}+\frac{\phi_{\mathrm{C}_{2}}}{\bar{V}_{\mathrm{C}_{2}}}=\frac{\phi_{\mathrm{C} 1}+\phi_{\mathrm{C}}}{2 \bar{V}_{\mathrm{C}_{1}}}+\frac{\phi_{\mathrm{B}}}{\bar{V}_{\mathrm{B}}}+\frac{\phi_{\mathrm{A}}}{\bar{V}_{\mathrm{A}}}
$$

As shown in many thermodynamic textbooks (for example, Prigogine and Defay ${ }^{31}$ ) the chemical potential of stoichiometric component $\mathrm{C}$ is equal to the chemical potential of the monomeric species in the solution

$$
\mu_{\mathrm{C}}=\mu_{\mathrm{C}_{1}}
$$

(28) H. Renon and J. M. Prausnitz, Chem. Eng. Sci., 22, 299 (1967); 22, 1891E (1967).

(29) I. Nagata, Z. Phys. Chem. (Leipzig), 252, 305 (1973).

(30) I. Nagata, Z. Phys. Chem. (Leipzig), 254, 273 (1973).

(31) I. Prigogine and R. Defay, "Chemical Thermodynamics", Wiley, New York, 1954
To obtain the customary excess properties of the solution, pure substance $\mathrm{C}$ must be taken as the new reference state

$$
\begin{aligned}
& \mu_{\mathrm{C}}-\mu_{\mathrm{C}}^{0}=R T\left[\ln \left(\phi_{\mathrm{C}_{1}} / \phi_{\mathrm{C}_{1}}^{0}\right)-\frac{\bar{V}_{\mathrm{C}_{1}}}{\hat{V}_{\text {soln }}}+\frac{\bar{V}_{\mathrm{C}_{1}}}{\hat{V}_{\text {soln }}^{0}}\right]+ \\
& \bar{V}_{\mathrm{C}_{1}}\left[\phi_{\mathrm{A}}\left(1-\phi_{\mathrm{C}_{1}}\right) A_{\mathrm{AC}_{1}}+\phi_{\mathrm{B}}\left(1-\phi_{\mathrm{C}_{1}}\right) A_{\mathrm{BC}_{1}}-\phi_{\mathrm{A}} \phi_{\mathrm{B}} A_{\mathrm{AB}}-\right. \\
& \left.\phi_{\mathrm{A}} \phi_{\mathrm{C}_{2}} A_{\mathrm{AC}_{2}}-\phi_{\mathrm{B}} \phi_{\mathrm{C}_{2}} A_{\mathrm{BC}_{2}}\right]
\end{aligned}
$$

Combining eq $9-12$, we write the excess Gibbs free energy as

$$
\begin{aligned}
& \Delta G^{\text {ex }}=R T\left[n_{\mathrm{A}} \ln \left(\phi_{\mathrm{A}} / X_{\mathrm{A}}\right)+n_{\mathrm{B}} \ln \left(\phi_{\mathrm{B}} / X_{\mathrm{B}}\right)+\right. \\
& n_{\mathrm{C}} \ln \left(\phi_{\mathrm{C}_{1}} / \phi^{0}{ }_{\mathrm{C}_{1}} X_{\mathrm{C}}\right)+n_{\mathrm{B}}+n_{\mathrm{A}}-\frac{n_{\mathrm{A}} \bar{V}_{\mathrm{A}}+n_{\mathrm{B}} \bar{V}_{\mathrm{B}}+n_{\mathrm{C}} \bar{V}_{\mathrm{C}}}{\hat{V}_{\mathrm{soln}}} \\
& \left.+\frac{n_{\mathrm{C}} \bar{V}_{\mathrm{C}}}{\hat{V}_{\mathrm{soln}}^{0}}\right]+\left(n_{\mathrm{A}} \bar{V}_{\mathrm{A}}+n_{\mathrm{B}} \bar{V}_{\mathrm{B}}+n_{\mathrm{C}} \bar{V}_{\mathrm{C}}\right)^{-1}\left[n_{\mathrm{A}} \bar{V}_{\mathrm{A}} n_{\mathrm{B}} \bar{V}_{\mathrm{B}} A_{\mathrm{AB}}\right. \\
& \left.+n_{\mathrm{A}} \bar{V}_{\mathrm{A}} n_{\mathrm{C}} \bar{V}_{\mathrm{C}} A_{\mathrm{AC}_{\mathrm{s}}}-n_{\mathrm{B}} \bar{V}_{\mathrm{B}} n_{\mathrm{C}} \bar{V}_{\mathrm{C}} A_{\mathrm{BC}_{1}}\right]
\end{aligned}
$$

where

$$
X_{\mathrm{i}}=n_{\mathrm{i}} /\left(n_{\mathrm{A}}+n_{\mathrm{B}}+n_{\mathrm{C}}\right) \quad n_{\mathrm{C}}=n_{\mathrm{C}_{1}}+2 n_{\mathrm{C}_{2}}
$$

For a system obeying eq 13 , the activity coefficient of component $A$ at infinite dilution is

$$
\begin{aligned}
& R T \ln \gamma_{\mathrm{A}(\mathrm{BC})}^{\infty}=R T\left[\ln \left(\frac{\bar{V}_{\mathrm{A}}}{X_{\mathrm{B}} \bar{V}_{\mathrm{B}}+X_{\mathrm{C}} \bar{V}_{\mathrm{C}}}\right)+1-\right. \\
&\left.\frac{\bar{V}_{\mathrm{A}}}{\hat{V}_{\mathrm{soln}}}\right]+\bar{V}_{\mathrm{A}}\left[\phi_{\mathrm{B}} A_{\mathrm{AB}}+\phi_{\mathrm{C}} A_{\mathrm{AC}_{1}}-\phi_{\mathrm{B}} \phi_{\mathrm{C}} A_{\mathrm{BC}_{1}}\right]
\end{aligned}
$$

the mole fraction and volume fraction compositions are now calculated as if the solute were not present. The $A_{\mathrm{AB}}$ and $A_{\mathrm{AC}}$ interaction parameters can be eliminated from the model via the infinite dilution activity coefficients in the pure solvents $\gamma_{\mathrm{A}(\mathrm{B})}^{\infty}$ and $\gamma_{\mathrm{A}(\mathrm{C})}^{\infty}$

$$
\begin{aligned}
& \ln \gamma_{\mathrm{A}(\mathrm{BC})}^{\infty}=\phi_{\mathrm{B}} \ln \gamma_{\mathrm{A}(\mathrm{B})}^{\infty}-\phi_{\mathrm{C}} \ln \gamma^{\infty}{ }_{\mathrm{A}(\mathrm{C})}+ \\
& \quad \ln \frac{\left(\bar{V}_{\mathrm{B}}\right)^{\phi_{\mathrm{B}}}\left(\bar{V}_{\mathrm{C}}\right)^{\phi_{\mathrm{C}}}}{X_{\mathrm{B}} \bar{V}_{\mathrm{B}}+X_{\mathrm{C}} \bar{V}_{\mathrm{C}}}-\frac{\bar{V}_{\mathrm{A}}\left(\phi_{\mathrm{C}_{1}}-\phi_{\mathrm{C}} \phi^{0}{ }_{\mathrm{C}_{\mathrm{L}}}\right)}{2 \bar{V}_{\mathrm{C}}}-\frac{\bar{V}_{\mathrm{A}} \phi_{\mathrm{B}} \phi_{\mathrm{C}} A_{\mathrm{BC}_{1}}}{R T}
\end{aligned}
$$

where $\phi_{\mathrm{C}_{1}}$ and $\phi_{\mathrm{C}_{1}}^{0}$ refer to the monomer concentration in the binary solvent and pure liquid $\mathrm{C}$, respectively

$$
\begin{gathered}
\phi_{\mathrm{C}_{1}}=\frac{\bar{V}_{\mathrm{C}_{1}}}{4 K_{\mathrm{D}}}\left[-1+\left(1+8 K_{\mathrm{D}} \phi_{\mathrm{C}} / \bar{V}_{\mathrm{C}_{1}}\right)^{1 / 2}\right] \\
\phi_{\mathrm{C}_{1}}^{0}=\frac{\bar{V}_{\mathrm{C}_{1}}}{4 K_{\mathrm{D}}}\left[-1+\left(1+8 K_{\mathrm{D}} / \bar{V}_{\mathrm{C}_{1}}\right)^{1 / 2}\right]
\end{gathered}
$$

and $K_{\mathrm{D}}$ is the molar dimerization constant.

Gas-liquid partition coefficients can be related to activity coefficients through the definition

$$
K_{\mathrm{R}}=\frac{R T Q}{P_{\mathrm{A}}^{0} \gamma_{\mathrm{A}}^{\infty} \bar{V}_{\mathrm{solv}}}
$$

in which $P_{A}^{0}$ is the equilibrium vapor pressure of the solute at the specified temperature and $Q$ is a temperature-dependent term involving the molar volume of the pure solute and the second virial coefficients of the solute and carrier gas. When this relationship is used, eq 15 becomes

$$
\begin{aligned}
& \ln K_{\mathrm{R}(\mathrm{BC})}=\phi_{\mathrm{B}} \ln K_{\mathrm{R}(\mathrm{B})}^{0}+\phi_{\mathrm{C}} \ln K_{\mathrm{R}(\mathrm{C})}^{0}+ \bar{V}_{\mathrm{A}} \phi_{\mathrm{B}} \phi_{\mathrm{C}} A_{\mathrm{BC}_{1}} \\
& \frac{\bar{V}_{\mathrm{A}}\left(\phi_{\mathrm{C}_{1}}-\phi_{\mathrm{C}} \phi_{\mathrm{C}_{1}}^{0}\right)}{2 T}+\frac{\bar{V}_{\mathrm{C}}}{R T}
\end{aligned}
$$




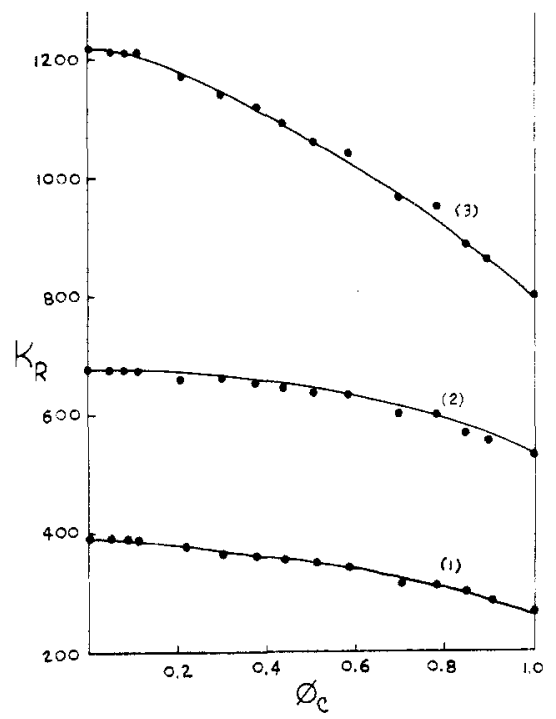

Floure 1. Plot of $K_{\text {ag }}$ against $\phi_{C}$ for $n$-hexane (1), cyclohexane (2), and $n$-heptane (3) solutes with solutions of $N, N$-dibutyl-2-ethythexylamide and $n$ hexadecane at $30^{\circ} \mathrm{C}$. The solid lines are calculated from eq 16 with $K_{\mathrm{D}}=0.2 \mathrm{dm}^{3} / \mathrm{mol}$ and $A_{\mathrm{BC}_{1}}=1.2 \mathrm{cal} / \mathrm{cm}^{3}$.

In the absence of dimerization, $K_{\mathrm{D}}=0$, the above expression reduces to the equation

$$
\ln K_{\mathrm{R}(\mathrm{BC})}=\phi_{\mathrm{B}} \ln K_{\mathrm{R}(\mathrm{B})}^{0}+\phi_{\mathrm{C}} \ln K_{\mathrm{R}(\mathrm{C})}^{0}+\frac{\bar{V}_{\mathrm{A}} \phi_{\mathrm{B}} \phi_{\mathrm{C}} A_{\mathrm{BC}}}{R T}
$$

derived earlier ${ }^{16}$ for systems containing only nonspecific interactions.

Calculations with various values for the dimerization constant reveal that the correction term is positive and it becomes more significant with increasing solute size. For values of $\bar{V}_{\mathrm{A}} / \bar{V}_{\mathrm{C}}=0.5$ and $K_{\mathrm{D}} / \bar{V}_{\mathrm{C}}=1.4$, partition coefficients calculated from eq 16 differ from those of eq 17 by only $2 \%$. Judicious selection of a new binary interaction parameter $A_{\mathrm{BC}}^{\prime}$ enables eq 17 to mathematically compensate for such a small difference, and thus further illustrates the difficulties in separating chemical and physical effects, especially for weak association complexes.

\section{Discussion}

Experimental gas-liquid partition coefficients of various solutes on $n$-hexadecane $+N, N$-dibutyl-2-ethylhexylamide and $n$-octadecane $+N, N$-dibutyl-2-ethylhexylamide mixtures provide an excellent opportunity to test eq 16 as the amide has been reported to dimerize in solution. As shown in Figures 1 and 2, eq $16\left(K_{\mathrm{D}}=0.2 \mathrm{dm}^{3} / \mathrm{mol}\right)$ describes the experimental data at $30^{\circ} \mathrm{C}$ everywhere to within $2 \%$, approximately the same degree of precision noted by Chien et al. for eq 6 . Increasing the binary interaction parameter slightly allows eq 17 to fit the chromatographic data to within experimental uncertainty. ${ }^{32}$ As a result, the controversy regarding the true thermodynamic description of

(32) During the course of these calculations, I noted that eq 4, with $K_{\mathrm{R}(\mathrm{C})}^{\prime}=K_{\mathrm{R}(\mathrm{C})} /\left(1+K_{\mathrm{AC}}^{\prime}\right)$, gave excellent agreement $( \pm 3 \%)$ with experiment for the chloroalkane solutes on both $n$-hexadecane $+N, N$-dibutyl-2-ethylhexylamide and $n$-octadecane $+N, N$-dibutyl-2-ethylhexylamide mixtures. For chloroform the values of $K^{\prime}$ ic ranged from 6.3 at $50^{\circ} \mathrm{C}$ to 11.5 at $20^{\circ} \mathrm{C}$. Chien et al. 17 had stated earlier that a similar conventional solution model, eq 13 of ref 17 , required negative equilibrium constants to describe the experimental partition coefficients. Since the two solution models are almost identical, I attribute the negative values to the method of data reduction and not to the failure of nonelectrolyte solution models. In my data analysis, the partition coefficients in the pure solvents are considered "perfect" values and $K_{\mathrm{AC}}^{\prime}$ is calculated near $\phi_{\mathrm{B}} \approx 0.5$

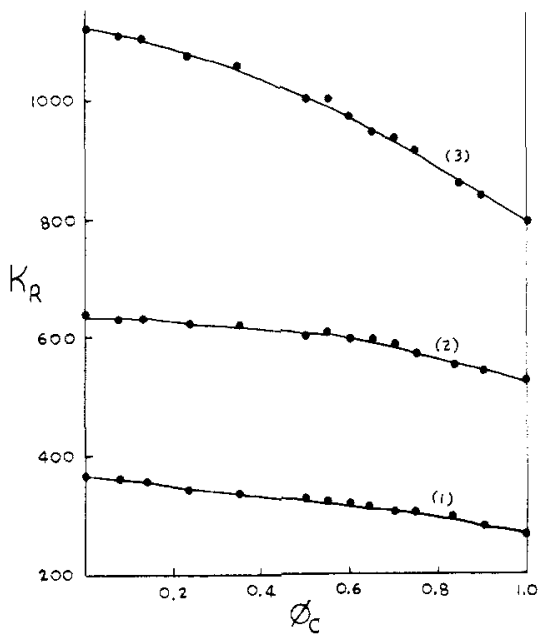

Flgure 2. Plot of $K_{\mathrm{R}(B C)}$ against $\phi_{\mathrm{C}}$ for $n$-hexane (1), cyciohexane (2), and $n$-heptane (3) solutes with solutions of $N, N$-dibutyl-2-ethylitexylamide and $n$-octadecane at $30^{\circ} \mathrm{C}$. The solid lines are calculated from eq 16 with $K_{\mathrm{D}}=0.2 \mathrm{dm}^{3} / \mathrm{mol}$ and $A_{\mathrm{BC}},=0.8 \mathrm{cal} / \mathrm{cm}^{3}$.

mixed-ligand phases remains unresolved, at least with respect to chromatographic applications. From an entirely speculative standpoint though, the method of column preparation may play an important role in determining how binary solvents are described. This idea becomes more plausible in light of a study by Chien, Laub, and Kopecni ${ }^{33}$ which indicated that partition coefficients on mechanically mixed packings [(support + B) plus (support $+C)$ are not necessarily identical with partition coefficients obtained with intimately blended solvents [support $+(\mathrm{B}+\mathrm{C})]$. The microscopic partition model assumes that the solvent components are mutually immiscible and eq 1 and 6 derived from this model are expected to be most applicable with mechanically mixed packings, where the phases presumably remain physically separated on the column. Conventional nonelectrolyte solution models, such as the one discussed here, assume that the binary solvent is a homogeneous mixture and expressions derived from this model should be most applicable with intimately blended solvents. The literature does contain numerous chromatographic investigations; however, the method of column preparation is not described in sufficient detail to adequately test the above hypothesis. Several of the recently reported deviations from volume fraction linearity, though, were observed with intimately blended solvents. $., 17,34,35$ Determination of solute retention behavior on mechanically mixed columns prepared from these solvents certainly merits comprehensive study and evaluation.

Equations 16 and 17, because of their logarithmic nature, are ideally suited for calculations involving chromatographic separations where knowledge of relative retentions permits the prediction of column length and optimum solvent composition for resolution of a given mixture. The relative retention is defined as a ratio of the partition coefficients for each of two solvents

$$
\alpha_{\mathrm{A} / \mathrm{D}(\mathrm{i})}=K_{\mathrm{R}(\mathrm{i}), \mathrm{A}} / K_{\mathrm{R}(\mathrm{i}), \mathrm{D}}
$$

and for convenience the numerical value of $\alpha$ is always taken to be greater than or equal to one. If for some reason inversion should occur, the $K_{\mathrm{R}}$ ratio is simply inverted.

(33) C. F. Chien, M. M. Kopecni, and R. J. Laub, Anal. Chem., 52, 1402 (1980).

(34) E. F. Meyer and J. A. Meyer, J. Phys. Chem., 85, 94 (1981).

(35) R. Queignec and M. Cabanetos-Queignec, J. Chromatogr., 209, 345 (1981) 
The partition coefficients of two inert solutes (components $A$ and D) in binary mixtures can be estimated through eq 16 (or eq 17 depending on the self-associative characteristics of the solvent components), and when combined into eq 18 yields

$$
\begin{aligned}
\alpha_{\mathrm{A} / \mathrm{D}} & =\phi_{\mathrm{B}} \ln \frac{K_{\mathrm{R}(\mathrm{B}), \mathrm{A}}^{0}}{K_{\mathrm{R}(\mathrm{B}), \mathrm{D}}^{0}}+\phi_{\mathrm{C}} \ln \frac{K_{\mathrm{R}(\mathrm{C}), \mathrm{A}}^{0}}{K_{\mathrm{R}(\mathrm{C}), \mathrm{D}}^{0}}+ \\
& \frac{\left(\bar{V}_{\mathrm{A}}-\bar{V}_{\mathrm{D}}\right)\left(\phi_{\mathrm{C}_{1}}-\phi_{\mathrm{C}} \phi_{\mathrm{C}_{1}}^{0}\right)}{2 \bar{V}_{\mathrm{C}}}+\frac{\left(\bar{V}_{\mathrm{A}}-\bar{V}_{\mathrm{D}}\right) \phi_{\mathrm{C}} \phi_{\mathrm{B}} A_{\mathrm{BC}_{1}}}{R T}
\end{aligned}
$$

Inspection of eq 19 reveals the relative retention can be expressed in terms of the values in the pure solvents $\left(\alpha_{\mathrm{A} / \mathrm{D}(\mathrm{B})}^{0}\right.$ and $\left.\alpha_{\mathrm{A} / \mathrm{D}(\mathrm{C})}\right)$, the dimerization constant of the self-associating solvent, and the binary interaction parameter $A_{\mathrm{BC}_{1}}$. In many instances the differences in the molar volumes of the two solutes will be quite small and the relative retention can be estimated by a simple geo- metric volume fraction average

$$
\alpha_{\mathrm{A} / \mathrm{D}}=\left(\alpha_{\mathrm{A} / \mathrm{D}(\mathrm{B})}^{0}\right)^{\phi_{\mathrm{B}}\left(\alpha_{\mathrm{A} / \mathrm{D}(\mathrm{C})}^{0}\right)^{\phi_{\mathrm{C}}}}
$$

Predictive expressions based on eq 6 are more complex and require a priori knowledge of two additional parameters $K_{\mathrm{R}\left(\mathrm{C}_{1}\right), \mathrm{A}}^{0}-K_{\mathrm{R}\left(\mathrm{C}_{2}\right), \mathrm{A}}^{0}$ and $K_{\mathrm{R}\left(\mathrm{C}_{1}\right), \mathrm{D}}^{0}-K_{\mathrm{R}\left(\mathrm{C}_{2}\right), \mathrm{D} \text {. }}^{0}$

$\mathrm{By}$ way of conclusion, I remind readers that the expressions presented here are for inert solutes. Incorporation of solute-solvent complexation into the self-associating binary solvent model is relatively straightforward and will be pursued at a later time, after I have had the opportunity to assess the limitations of eq 16 with several nonchromatographic investigations. Any coherent theory of solutions should describe thermodynamic properties irrespective of the method of experimental determination. Gas-liquid chromatography represents just one of the experimental techniques for measuring activity coefficients and heats of solution.

\title{
Oxygenation of Ferrous Ions In Reversed Mlcelle and Reversed Microemulsion
}

\author{
Katsuya Inouye," Rleko Endo, Yoko Otsuka, Kelko Mlyashiro, Katsuml Kaneko, and Tatsuo Ishikawa \\ Department of Chemistry, Faculty of Science, Chlba University, Yayoicho, Chiba 260, Japan (Received: August 31, 1981)
}

\begin{abstract}
The Aerosol OT reversed micelle and the Schulman's reversed microemulsion with aqueous cores trapping dilute $\mathrm{Fe}^{2+}$ solution have been prepared and subjected to oxygenation by air at different temperatures between 30 and $70^{\circ} \mathrm{C}$. It was confirmed that the apparent rate of oxygenation reaction is enhanced for both the reversed micelle and reversed microemulsion by approximately $10^{2}-10^{3}$-fold of that in bulk solution. By the air oxidation of the reversed microemulsion, in particular, precipitates appeared from the water pools. Electron micrographs of the precipitates showed sharp needles which are likely to be $\mathrm{FeOOH}$ crystals, indicating the building of a strongly alkaline environment in the aqueous cores. The probable causes of rise in $\mathrm{pH}$ and the resulting acceleration of overall oxidation reaction have been suggested.
\end{abstract}

\section{Introduction}

Aggregates between surface active molecules and aqueous microcores formed in nonpolar solvent are called reversed micelles, when the diameter of aqueous phase is normally in the range 10-100 $\AA .{ }^{1}$ Similar aggregates with larger dimensions of aqueous pool ranging from $10^{2}$ to $10^{3}$ $\AA$ are termed $\mathrm{W} / \mathrm{O}$ reversed microemulsions. ${ }^{2}$ In both systems, the aqueous phases surrounded by a layer of surfactant molecules are believed to provide particular restricted fields, where many reactions occurring inside the core are much enhanced.

The similarity of the reversed micelle system to biological aqueous microphases in membranes has stimulated research in model experiments of enzymatic actions. ${ }^{3}$ Although the real enzymatic reaction has to be considered from multiple factors, the aqueous cores of the reversed micelle seem to promote catalytic reactions by the surrounding surfactant itself and to provide a reaction site or a reaction field inside the core. In this context, many organic reactions have been examined in various reversed micelle systems. ${ }^{1}$ Very little attention, however, has been paid to inorganic reaction except for some investigations on the behavior of complexes of $\mathrm{Cr}^{3+}, \mathrm{Co}^{2+}$, and $\mathrm{Ni}^{2+}$

(1) J. H. Fendler and E. J. Fendler, "Catalysis in Micellar and Macromolecular Systems", Academic Press, New York, 1975.

(2) L. M. Prince, "Microemulsion”, Academic Press, New York, 1977.

(3) J. H. Fendler, F. Nome, and H. C. Van Woert, J. Am. Chem. Soc. 96, 6745 (1974). ions. ${ }^{4-7}$ More recently, Sunamoto ${ }^{8,9}$ suggested the importance of the interaction between cationic metal ions, such as $\mathrm{Co}^{2+}$ and $\mathrm{Cu}^{2+}$, and substrate molecules in some complicated mechanism, causing a high reaction rate in the reversed micelle core.

Still fewer studies have been tried on the reactions in microemulsions, and even more scarce are studies on reactions in the reversed microemulsion, in spite of a high potentiality for membrane mimetic systems of photochemical reactions, as surveyed recently by Fendler. ${ }^{10}$

In the present study, we determined the rate of air oxygenation of ferrous ion, entrapped in the aqueous cores of reversed micelles and reversed microemulsions, in order to confirm whether the reaction is enhanced. The authors' interest was initiated not only by investigating the polynuclear reaction of ferrous ion in such a particular environment, but also by probable mimicking of the ferritin formation in interior cores of apoferritin. The latter has been investigated extensively by use of iron-free apo-

(4) C. J. O'Connor, E. J. Fendler, and J. H. Fendler, J. Am. Chem. Soc., 95, 600 (1973).

(5) C. J. O'Connor, E. J. Fendler, and J. H. Fendler, J. Am. Chem. Soc., 96, 370 (1974).

(6) A. D. James and B. H. Robinson, J. Chem. Soc., Faraday Trans. $1,74,10$ (1978).

(7) B. H. Robinson and D. C. Steytler, J. Chem. Soc., Faraday Trans. $1,75,481$ (1979).

(8) J. Sunamoto, H. Kondo, and K. Akimaru, Chem. Lett., 821 (1978).

(9) J. Sunamoto, private communications.

(10) J. H. Fendler, J. Phys. Chem., 84, 1485 (1980). 